\title{
The social and thermal competence of wild vervet monkeys
}

2

3 Richard McFarland ${ }^{1,2}$, Peter Henzi ${ }^{3,4}$, Louise Barrett ${ }^{3,4}$

4

$5 \quad{ }^{1}$ Department of Anthropology, University of Wisconsin-Madison, United States.

$6 \quad{ }^{2}$ Brain Function Research Group, School of Physiology, University of the Witwatersrand, South

7 Africa.

$8{ }^{3}$ Department of Psychology, University of Lethbridge, Canada.

$9{ }^{4}$ Applied Behavioural Ecology and Ecosystems Research Unit, University of South Africa,

10 South Africa.

11

12 Words: 2560 words. 
13 As long-lived, slowly reproducing animals, primates face numerous ecological challenges to

14 their survival and successful reproduction. The majority of primates live in groups, an adaptation

15 widespread in the animal kingdom that can provide improved predator defense, food acquisition,

16 and access to mating opportunities; all of which can contribute to an individual's fitness.

17 Compared to other animal taxa, however, primates are intensely social, spending a significant

18 amount of time forming and maintaining social relationships within their group (Dunbar 1991).

19 There is evidence to suggest that such relationships are evolutionarily adaptive: more socially

20 integrated individuals experience improved rates of survival and reproductive success (Silk et al.

21 2009; Schülke et al. 2010; McFarland \& Majolo 2013; McFarland et al 2017). One argument for

22 the adaptive value of social relationships is that they help offset the inevitable costs of group-

23 living, which manifest in terms of increased competition for resources, such as food, safe spatial

24 positions and mates. The patterning of social life thus represents the negotiation of individual

25 needs within constraints imposed by others. This, in turn, is argued to have selected for a high

26 degree of developmental plasticity and behavioral flexibility among the anthropoid primates in

27 particular.

29 In addition to these social challenges, climatic variability is also known to exert strong selective 30 pressures on ecology, behavior and physiology, and has similarly been argued to select for

31 plasticity in the form of developmental norms of reaction, as well as individual behavioral

32 flexibility. Most notably, it has been argued that selection for the ability to cope with and

33 respond to rapid and extensive environmental change can explain patterns of hominin evolution,

34 and the marked flexibility of humans compared to other animals (Potts 1998; Maslin et al. 2015).

35 Understanding the scope and limits of primates' ability to cope with environmental variability is 
36 thus the focus of much socioecological research which, broadly speaking, attempts to answer the

37 question of how primates solve their ecological problems with respect to the opportunities and

38 constraints of social life. Such questions are becoming ever more pressing in the context of the

39 imminent threat of global climate change to our planet's biodiversity (Thompson et al. 2005;

40 Wiederholt \& Post 2010). Approximately 60\% of species are now threatened with extinction,

41 with $75 \%$ of primate species experiencing a declining population (Estrada et al. 2017).

42

43 Our own research focuses on the behavioral and physiological strategies used by primates to deal

44 with environmental variation, both via changes in resource availability and in terms of direct

45 climatic effects. Specifically, we focus on the thermal physiology wild vervets (Chlorocebus

46 pygerythrus), investigating whether social life compounds or ameliorates the demands made by

47 the thermal environment. Vervet monkeys are ideal model organisms for a study of this type

48 because they are obligatorily social, experience a wide temperature range in arid environments,

49 and manifest a range of specialised behavioral thermoregulatory adaptations. To date, most

50 studies on the thermal physiology of large mammals (which, generally speaking, means non-

51 rodent species) have focused on species that are either solitary or show limited sociality (Fuller

52 et al. 2016). Unlike these species, group-living primates potentially face a compromise between

53 the strategies that promote physiological homeostasis and those that optimise the benefits of

54 group-living. Our study is unique, therefore, in allowing us to probe the intersection of our

55 animals' ecological and social strategies, the degree of flexibility they display, and what

56 consequences this holds for survival and reproductive success. This, in turn, provides vital

57 information concerning the long-term viability of vervets populations in the face of ongoing

58 climate change. 
60 Since 2008, we have been studying three groups of vervets on the Samara Private Game Reserve

61 in the Nama Karoo, Eastern Cape, South Africa, combining behavioral, ecological, and body

62 temperature data, to investigate individual differences in thermal competence, sociability and

63 fitness-related traits. Samara is characterized as a high-altitude, semi-arid desert, with vervet

64 presence mostly restricted to narrow strips of riparian Acacia karroo woodland along non-

65 perennial streams (Pasternak et al. 2013). The region experiences hot, wet summers (November-

66 March) and cold, dry winters (June - August), with minimum and maximum temperatures

67 ranging between -5 and $40{ }^{\circ} \mathrm{C}$ (McFarland et al. 2014). This region of South Africa is also prone

68 to intermittent periods of drought (Hoffman et al 2009). Vervets have inhabited the semi-arid

69 karoo biome of South Africa since at least the $18^{\text {th }}$ century, and despite these extreme

70 environmental conditions, are found at high population densities, with higher than average group

71 sizes compared to other vervet populations in Africa (Pasternak et al. 2013). The rapidity of

72 change in arid-zone thermal environments offers an excellent and feasible opportunity to track

73 the targets of natural selection for thermal competence.

74

75 The majority of studies that have explored the effects of environmental variability on primates

76 have tended to focus on the effect of climatic variables on behaviors crucial for survival (e.g.,

77 resting, foraging and social activity: Hill et al. 2003; Campos \& Fedigan 2009; Korstjens et al.

78 2010; Majolo et al. 2013; McFarland et al. 2014). Importantly, only a few studies have directly

79 collected body temperature measurements from free-ranging primates (Brain \& Mitchell 1999;

80 Mzilikaze et al. 2006; Dausman et al. 2004; Nowack et al. 2010; Thompson et al. 2014).

81 Although these studies have provided important insights, they have been restricted to few study 
82 subjects, short study periods, or lacked detailed simultaneous data on the primates' behavior,

83 feeding ecology and environment. Moreover, most of these studies used skin or subcutaneous

84 body temperature measurements, which can be significantly affected by ambient temperature,

85 ultimately providing less accurate accounts of the effect of climate on core body temperature.

86 Consequently, the existing literature provides limited insight into the effects of environmental

87 variability on animal's ability to thermoregulate efficiently. Our study of vervets is the first to

88 use bio-logging technology to collect continuous long-term measurements of core body

89 temperature from multiple individuals in a wild population, whilst simultaneously collecting

90 detailed records of their behavior and ecology (McFarland et al. 2013). Bio-logging has allowed

91 us to determine how efficiently a monkey regulates its body temperature (i.e., daily body

92 temperature averages, amplitudes, minima and maxima) when exposed to environmental and

93 social stressors.

94

95 Like all mammals, vervet monkeys are homeothermic, and typically maintain a body temperature

96 ranging between 37 and $39^{\circ} \mathrm{C}$ (Lubbe et al. 2014). Homeothermy is the ability to maintain a core

97 body temperature within a narrow range when subjected to a wide range of environmental

98 temperatures. This is achieved through a combination of autonomic and behavioral processes.

99 Autonomic processes, involving the activation of pathways in the anterior hypothalamus to

100 regulate the balance of heat production and loss, can be costly in terms of energy expenditure at

101 low temperatures, and water loss (i.e., evaporative sweat) at high temperatures. To help alleviate

102 these costs, animals can also engage in behaviors that help to keep their body warm or cold, such

103 as changing posture or selecting appropriate microclimates. Vervets use various behavioral

104 strategies in their attempt to buffer themselves from environmental variability. During warmer 
105 periods, vervets spend significantly more time resting at the expense of feeding (McFarland et al.

106 2014). To reduce the effect of the heat, vervets also seek out shade, hug cool river rocks, retreat

107 into aardvark burrows, and spend time swimming (Fig. 1). In cooler conditions, vervets can be

108 seen sun-basking or huddling with other group members, as they try to maximize heat gain, or

109 minimize heat-loss, respectively (Fig. 1). Vervets devote significantly more time to feeding, at

110 the expense of resting, as part of their attempt to meet the energetic demands of colder conditions

111 (McFarland et al. 2014).

112

113 So far, we have established that vervet monkeys in the Eastern Cape are more prone to cold

114 stress than heat stress (Lubbe et al. 2014; McFarland et al. 2015; Henzi et al. 2017). Specifically,

115 vervets display reduced thermoregulatory efficiency, experiencing lower, and increasingly

116 hypothermic body temperatures, when temperatures are cold (i.e., the winter months). Moreover,

117 we also see the greatest inter-individual variability in thermal competence at this time of year,

118 and these effects become more pronounced as winter progresses and the energetic demands

119 persist. The challenge of the cold is to minimize heat-loss to the environment whilst maximizing

120 heat-gain and energy consumption. These problems are exacerbated at night, when vervets

121 retreat to the trees and the risk of predation from land predators is highest (such predators present

122 a significant risk at our study site, where vervets are exposed to black-backed jackal (Canis

123 mesomelas), caracal (Caracal caracal) and several birds of prey: Pasternak et al. 2013;

124 Ducheminsky et al. 2014). With minimal foraging capability, there is little a monkey can do to

125 buffer itself against cold night-time temperatures. The only strategy available is to find another

126 group member, and engage in huddling. Nocturnal huddling has been observed to be an

127 important adaptation to a range of primate species living in temperate climates (Takahashi 1997; 
128 Ogawa \& Takahashi 2003; Li et al. 2010; McFarland \& Majolo 2013). In line with these

129 previous findings, our study has shown that thermal competence is positively predicted by an

130 individual's number of social partners (McFarland et al. 2015; Henzi et al. 2017); a finding we

131 interpret as reflecting variation in the number of potential huddling partners an animal can call

132 on in cold temperatures. Interestingly, for males, we also found that their tenure length in the

133 troop explains some of the variance in thermoregulatory competence. This suggests that learning

134 and selecting suitable microhabitats at night may also play a role in improving thermoregulatory

135 efficiency (Henzi et al. 2017). In a tangential experimental study of the heat-transfer

136 characteristics of vervet monkey pelts, we found that grooming behavior (Fig. 1) apparently

137 minimizes heat loss by increasing the pelt's insulative properties (i.e., loft), thus enabling

138 animals to compensate for moderate environmental cooling, without increasing the demand of

139 their metabolism (McFarland et al. 2016).

141 During hot conditions, vervets show remarkable efficiency in keeping their body temperature

142 stable, and avoid significant bouts of hyperthermia (Lubbe et al. 2014). It is not surprising that

143 vervets cope better with heat given that, as noted above, they have more strategies for dissipating

144 heat than conserving it. In addition to bio-logging the vervets' temperature, we also use the same

145 logging technology to measure environmental temperatures, and have found that, when vervets

146 seek shade during the hottest part of the day, they select microclimates that can be up to twenty

147 degrees cooler than direct exposure to the sun. Importantly, our vervets also have regular access

148 to drinking water, which facilitates the sweat production necessary to dissipate heat in these

149 conditions. Although largely a water-dependent species - vervets' geographical distribution is

150 restricted to riverine habitats or artificial water sources maintained by humans - vervets can 
151 show remarkable resilience to periods of water unavailability, a circumstance not uncommon

152 within their semi-arid, drought prone habitats. Prior to the beginning of our thermoregulation

153 study (and partly the impetus for it), the vervets experienced a period of intense drought, during

154 which there was very little free-standing water present in the troops' territories (McDougall et al.

155 2010). As a consequence, there was a marked increase in aggression over access to the little

156 water that was present, despite these being small seepage points that offered little reward. More

157 interesting, however, is what happened at the point when all free-standing water dried up

158 completely. One of our troops was observed to leave their territory on the day after all the free-

159 standing water dried up, venturing away from the river, along an exposed ridge unoccupied by

160 any other vervet troops. They then returned to the river approximately $750 \mathrm{~m}$ from their territory

161 boundary, bypassing the ranges of four other groups, and entering an area containing a series of

162 large pools. Our supposition is that the animals were led there by a male immigrant returning to

163 his former territory. The willingness of other group members to follow this male, along with the

164 intense aggression over largely unproductive water sources, suggests that vervets perceive direct

165 access to water as crucial. In another of our groups, the loss of standing water did not prompt

166 immediate movement in search of water. Instead, the group persisted without water for over a

167 month by targeting succulent plants and licking dew from rocks and grass. Eventually, this group

168 similarly followed an immigrant male to the water outside of their home territory. Visits by the

169 two troops were then both regular and frequent, and the monkeys finally began sleeping at the

170 new site. During this period, we observed no drought-related deaths, but it is clear that, had the

171 monkeys not discovered a source of free-standing water, their survival would have been

172 compromised. In this respect, the ability to observe and copy the behavior of animals with a

173 broader experience of the surrounding area reflects another benefit of sociality. 
175 Understanding how social influences on thermoregulation tie into vervet social dynamics is a

176 topic we are now exploring in more detail. The Samara vervets display some interesting

177 differences in their social behavior compared to the classic studies from Amboseli, which may be

178 related to larger group sizes at our site (Henzi et al. 2013). Specifically, Samara females show

179 clear grooming and proximity preferences for certain individuals, but these patterns are not easily

180 explained by the standard organizing principles of rank and kinship: our females do not groom

181 up the hierarchy, nor do they favor adjacently ranked females (i.e., those who are likely to be

182 kin). There is no relationship between females' spatial proximity to each other and their

183 probability of grooming (i.e., females do not simply groom whichever animal happens to be

184 convenient). We have, however, shown that females use grooming strategically to secure safe

185 spatial positions within the group: animals with larger grooming networks were less exposed to

186 predation risk, from which they benefitted both reduced vigilance and increased foraging time

187 (Josephs et al. 2016). It is also apparent, however, that there are large fluctuations in group size

188 over time at our site, which reflect variation in climatic conditions - periods of drought result in

189 increased rates of adult and infant mortality — and social patterns may thus vary accordingly. It

190 may be that female social strategies vary in accordance with both group size and prevailing

191 environmental conditions to produce cyclical patterns of variation over time: a possibility our

192 long-term data will allow us to investigate more thoroughly.

194 To date, the adaptive value of sociability among primates has often been attributed to more

195 sociable individuals being better able to deal with chronic social stress, which has a positive

196 impact on reproduction (Silk 2007; Brent et al. 2013). Collectively, our research on vervets 
197 suggests that climatic variability can also present a significant source of stress to primate groups,

198 and that more sociable individuals are better equipped to deal with such challenges. If more

199 sociable animals are better able to minimize the metabolic costs of thermoregulation, it is

200 probable that they are not only more likely to survive extreme environmental events, but these

201 savings in maintenance costs mean they also have more energy to invest in reproduction. Our

202 work therefore contributes to the growing body of evidence suggesting that sociability and

203 behavioral flexibility are evolutionarily adaptive traits, and are likely to play an important role in

204 promoting the ongoing viability of populations living in highly-variable, extreme environmental

205 conditions (Henzi et al. 2009; Henzi et al. 2013; McFarland \& Majolo 2013; Young et al. 2014;

206 McFarland et al. 2014, 2015; Young et al. 2017; Henzi et al. 2017; McFarland et al. 2017).

208 References

209 Brain C, Mitchell D. 1999. Body temperature changes in free-ranging baboons (Papio

210 hamadryas ursinus) in the Namib Desert, Namibia. International Journal of Primatology 20: 585-

211598.

212 Brent LJ. et al. 2013. Genetic origins of social networks in rhesus macaques. Scientific Reports

213 3: 1042.

214 Campos FA, Fedigan LM. 2009. Behavioural adaptations to heat stress and water scarcity in

215 white-faced capuchins (Cebus capucinus) in Santa Rosa National Park, Costa Rica. American

216 Journal of Physical Anthropology 138: 101-111.

217 Dausmann KH, Glos J, Ganzhorn JU, Heldmaier G. 2004. Physiology: Hibernation in a tropical

218 primate. Nature 429: 825-826. 
219 Ducheminsky N, Henzi SP, Barrett L. 2014. Responses of vervet monkeys in large troops to

220 terrestrial and aerial predator alarm calls. Behavioral Ecology 25: 1474-1484.

221 Dunbar RIM. 1991. Functional significance of social grooming in primates. Folia Primatologica

222 57: 121-131.

223 Estrada A, Garber PA, Rylands AB, Roos C, Fernandez-Duque E, Di Fiore A, Nekaris KAI,

224 Nijman V, Heymann EW, Lambert JE, Rovero F. 2017. Impending extinction crisis of the

225 world's primates: Why primates matter. Science Advances 3: e1600946.

226 Fuller A, Mitchell D, Maloney SK, Hetem RS. 2016. Towards a mechanistic understanding of

227 the responses of large terrestrial mammals to heat and aridity associated with climate change.

228 Climate Change Responses 3: 10.

229 Henzi SP, Hetem R, Fuller A, Maloney S, Young C, Mitchell D, Barrett L, McFarland R. 2017.

230 Consequences of sex-specific sociability for thermoregulation in male vervet monkeys during

231 winter. Journal of Zoology.

232 Henzi SP, Forshaw N, Boner R, Barrett L, Lusseau D. 2013. Scalar social dynamics in female

233 vervet monkey cohorts. Philosophical Transactions of the Royal Society B: Biological Sciences,

234 368: 20120351.

235 Henzi SP, Lusseau D, Weingrill T, Van Schaik CP, Barrett, L. 2009. Cyclicity in the structure of

236 female baboon social networks. Behavioral Ecology and Sociobiology 63: 1015-1021.

237 Hill RA, Barrett L, Gaynor D, Weingrill T, Dixon P, Payne H, Henzi SP. 2003. Day length,

238 latitude and behavioural (in) flexibility in baboons (Papio cynocephalus ursinus). Behavioral

239 Ecology and Sociobiology 53: 278-286.

240 Hoffman MT, Carrick PJ, Gillson L, West AG. 2009. Drought, climate change and vegetation

241 response in the succulent karoo, South Africa. South African Journal of Science 105: 54-60. 
242 Josephs N, Bonnell T, Dostie M, Barrett L, Henzi SP. 2016. Working the crowd: sociable vervets

243 benefit by reducing exposure to risk. Behavioral Ecology 27: 988-994.

244 Korstjens AH, Lehmann J, Dunbar RIM. 2010. Resting time as an ecological constraint on

245 primate biogeography. Animal Behaviour 79: 361-374.

246 Li D, Ren B, Grueter CC, Li B, Li M. 2010. Nocturnal sleeping habits of the Yunnan snub-nosed

247 monkey in Xiangguqing, China. American Journal of Primatology 72: 1092-1099.

248 Lubbe A, Hetem RS, McFarland R, Barrett L, Henzi SP, Mitchell D, Meyer LCR, Maloney SK,

249 Fuller A. 2014. Thermoregulatory plasticity in free-ranging vervet monkeys, Chlorocebus

250 pygerythrus. Journal of Comparative Physiology B 184: 799-809.

251 Majolo B, McFarland R, Young C, Qarro M. 2013. The effect of climatic factors on the activity

252 budgets of a temperate primate, the Barbary macaque (Macaca sylvanus). International Journal

253 of Primatology 34: 500-514.

254 Maslin MA, Shultz S, Trauth MH. 2015. A synthesis of the theories and concepts of early human

255 evolution. Philosophical Transactions of the Royal Society of London B: Biological Sciences

256 370: 20140064.

257 McDougall P, Forshaw N, Barrett L, Henzi SP. 2010. Leaving home: Responses to water

258 depletion by vervet monkeys. Journal of Arid Environments 74: 924-927.

259 McFarland R, Murphy D, Lusseau D, Henzi SP, Parker JL, Pollet TV, Barrett L. 2017. The

260 'strength of weak ties' among female baboons: fitness-related benefits of social bonds. Animal

261 Behaviour.

262 McFarland R, Henzi SP, Barrett L, Wanigaratne A, Coetzee E, Fuller A, Hetem RS, Mitchell D,

263 Maloney SK. 2016. Thermal consequences of increased pelt loft infer an additional utilitarian

264 function for grooming. American Journal of Primatology 78: 456-461. 
265 McFarland R, Fuller A, Hetem RS, Mitchell D, Maloney SK, Henzi SP, Barrett L. 2015. Social

266 integration confers thermal benefits in a gregarious primate. Journal of Animal Ecology 84: 871-

267878.

268 McFarland R, Barrett L, Boner R, Freeman NJ, Henzi SP. 2014. Behavioral flexibility of vervet

269 monkeys in response to climatic and social variability. American Journal of Physical

270 Anthropology 154: 357-364.

271 McFarland R, Hetem RS, Fuller A, Mitchell D, Henzi SP, Barrett L. 2013. Assessing the

272 reliability of biologger techniques to measure activity in a free-ranging primate. Animal

273 Behaviour 85: 861-866.

274 McFarland R, Majolo B. 2013. Coping with the cold: Predictors of survival in wild Barbary

275 macaques, Macaca sylvanus. Biology Letters 9: 20130428.

276 Mzilikazi N, Masters JC, Lovegrove BG. 2006. Lack of torpor in free-ranging southern lesser

277 galagos, Galago moholi: Ecological and physiological considerations. Folia Primatologica 77:

$278 \quad 465-476$.

279 Nowack J, Mzilikazi N, Dausmann KH. 2010. Torpor on Demand: Heterothermy in the Non-

280 Lemur Primate Galago moholi. PLoS ONE 5: e10797.

281 Ogawa H, Takahashi H. 2003. Triadic positions of Tibetan macaques huddling at a sleeping site.

282 International Journal of Primatology 24: 591-606.

283 Pasternak G, Brown LR, Kienzle S, Fuller A, Barrett L, Henzi SP. 2013. Population ecology of

284 vervet monkeys in a high latitude, semi-arid riparian woodland. Koedoe 55: 1-9.

285 Potts R. 1998. Variability selection in hominid evolution. Evolutionary Anthropology: Issues,

286 News, and Reviews 7: 81-96. 
287 Schülke O, Bhagavatula J, Vigilant L, Ostner J. 2010 Social bonds enhance reproductive success

288 in male macaques. Current Biology 20: 2207-2210.

289 Silk JB. 2007. The adaptive value of sociality in mammalian groups. Philosophical Transactions

290 of the Royal Society B 362: 539-559.

291 Silk JB, Beehner JC, Bergman TJ, Crockford C, Engh AL, Moscovice LR, Wittig RM, Seyfarth

292 RM, Cheney DL. 2009 The benefits of social capital: close social bonds among female baboons

293 enhance offspring survival. Proceedings of the Royal Society B 276: 3099-3104.

294 Takahashi H. 1997. Huddling relationships in night sleeping groups among wild Japanese

295 macaques in Kinkazan Island during winter. Primates 38: 57-68.

296 Thomas CD et al. 2004. Extinction risk from climate change. Nature 427: 145-148.

297 Thompson CL, Williams SH, Glander KE, Teaford MF, Vinyard CJ. 2014. Body temperature

298 and thermal environment in a generalized arboreal anthropoid, wild mantled howling monkeys

299 (Alouatta palliata). American Journal of Physical Anthropology 154: 1-10.

300 Wiederholt R, Post E. 2010. Tropical warming and the dynamics of endangered primates.

301 Biology Letters 6: 257-260.

302 Young C, Majolo B, Heistermann M, Schülke O, Ostner J. 2014. Responses to social and

303 environmental stress are attenuated by strong male bonds in wild macaques. Proceedings of the

304 National Academy of Sciences 111: 18195-18200.

305 Young C, McFarland R, Barrett L, Henzi SP. 2017. Formidable females and the power

306 trajectories of socially integrated male vervet monkeys. Animal Behaviour 125: 61-67. 
308 Figure 1. Behavioral responses of wild vervet monkeys to climatic variability.

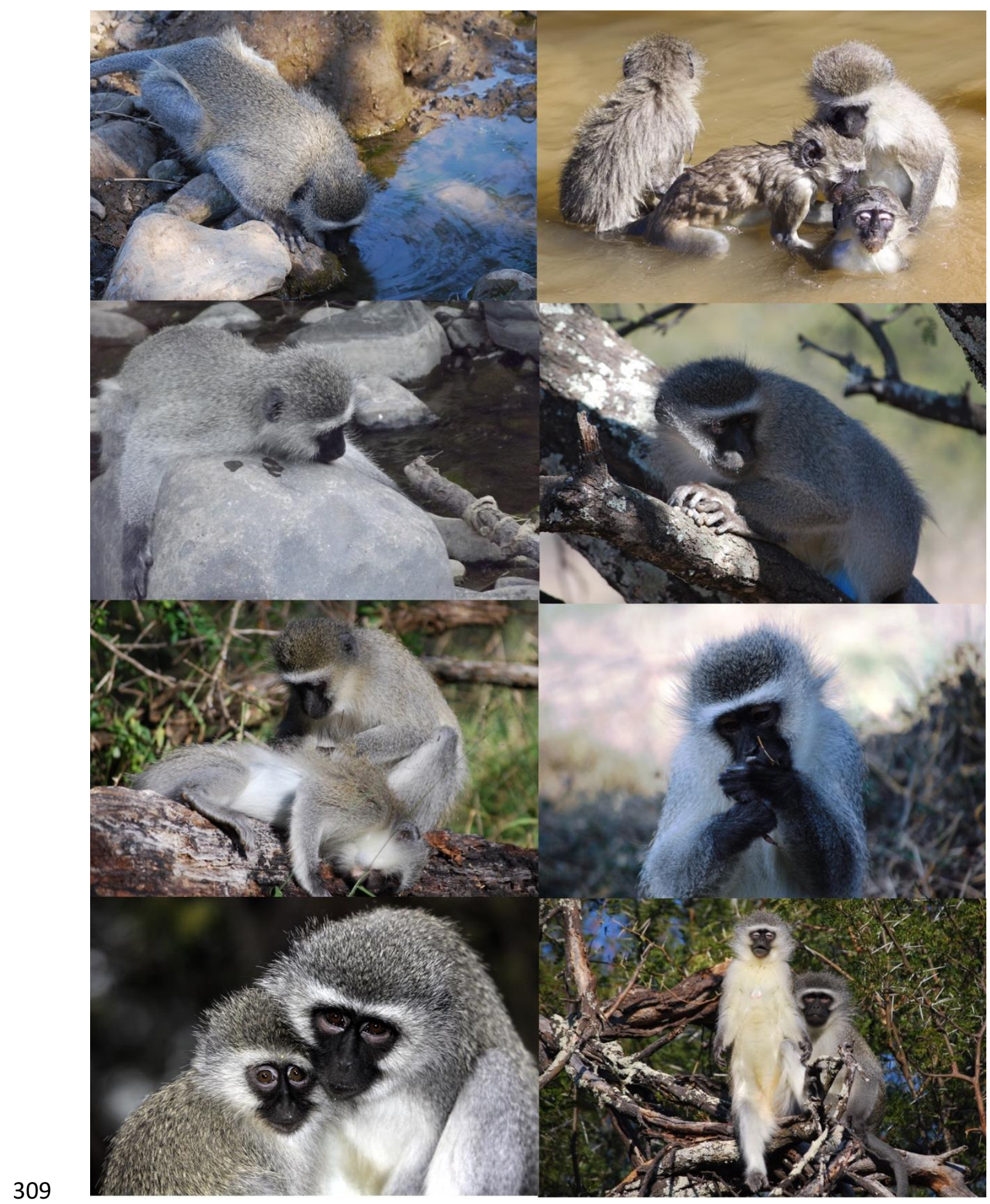

$310 *$ *eft to right: drinking, swimming, rock-hugging, resting in shade, grooming, feeding, huddling, and sun-basking. 